\title{
Digestive physiological outcomes related to polydextrose and soluble maize fibre consumption by healthy adult men
}

\author{
Brittany M. Vester Boler ${ }^{1}$, Mariana C. Rossoni Serao ${ }^{1}$, Laura L. Bauer ${ }^{1}$, Michael A. Staeger ${ }^{2}$, \\ Thomas W. Boileau ${ }^{2}$, Kelly S. Swanson ${ }^{1}$ and George C. Fahey $\mathrm{Jr}^{1 *}$ \\ ${ }^{1}$ Department of Animal Sciences, University of Illinois, 1207 West Gregory Drive, Urbana, IL 61801, USA \\ ${ }^{2}$ General Mills, Inc., Bell Institute of Health and Nutrition, 9000 Plymouth Avenue North, Minneapolis, MN 55427, USA
}

(Received 7 January 2011 - Revised 29 March 2011 - Accepted 29 March 2011 - First published online 31 May 2011)

\begin{abstract}
The objective of the present study was to evaluate digestive physiological outcomes elicited by functional fibres fed to healthy adult men. A total of twenty-one healthy adult men were utilised in a cross-over design. Each subject received polydextrose (PDX) or soluble maize fibre (SCF) (21 g/d) or no supplemental fibre (no fibre control; NFC) in a snack bar. Periods were $21 \mathrm{~d}$ and faeces were collected during the last $5 \mathrm{~d}$ of each period. Food intake, including fibre intake, did not differ among treatments. Flatulence $(P=0 \cdot 001)$ and distention $(P=0 \cdot 07)$ were greatest when subjects consumed PDX or SCF. Reflux was greater $(P=0.04)$ when subjects consumed SCF compared with NFC. All tolerance scores were low $(<2 \cdot 5)$, indicating only slight discomfort. Faecal ammonia, 4-methylphenol, indole and branchedchain fatty acid concentrations were decreased $(P<0 \cdot 01)$ when subjects consumed the functional fibre sources compared with NFC. Faecal acetate, propionate and butyrate concentrations were lower $(P<0.05)$ when subjects consumed PDX compared with SCF and NFC. Faecal pH was lower $(P=0 \cdot 01)$ when subjects consumed SCF compared with NFC, while PDX was intermediate. Faecal wet weight was greatest $(P=0.03)$ when subjects consumed SCF compared with NFC. Faecal dry weight tended to be greater $(P=0 \cdot 07)$ when subjects consumed PDX compared with NFC. The functional fibres led to 1.4 and $0.9 \mathrm{~g}$ (PDX and SCF, respectively) increases in faecal dry mass per g supplemental fibre intake. Bifidobacterium spp. concentrations were greater $(P<0 \cdot 05)$ when subjects consumed SCF compared with NFC. These functional fibres appear to be beneficial to gut health while leading to minimal gastrointestinal upset.
\end{abstract}

Key words: Fibre: Polydextrose: Soluble maize fibre: Fermentation

Fibre is known to have positive effects on gastrointestinal health and has been determined to have a link to decreased disease risk (CHD, colorectal cancer, breast cancer). Dietary fibre consumption in the USA is $12-18 \mathrm{~g} / \mathrm{d}$, which is well below the recommended adequate intake of $25 \mathrm{~g} / \mathrm{d}$ for women and $38 \mathrm{~g} / \mathrm{d}$ for men ${ }^{(1)}$. Little research currently exists regarding select functional soluble fibres such as polydextrose (PDX) and soluble maize fibre (SCF). Furthermore, there is debate as to whether these functional soluble fibres deliver known health benefits associated with 'traditional' dietary fibres. Additional fibre consumption can lead to increased gas production and overall gastrointestinal discomfort. Therefore, finding functional fibres that can be added to food products that minimally disturb gastrointestinal tolerance and acceptance of the product may result in increased fibre consumption by humans.

PDX is a randomly bonded polysaccharide of glucose, with an average degree of polymerisation of 12 . Soluble maize fibre is made from maize starch and contains oligosaccharides with random glycosyl bonds and may contain minor amounts of monosaccharides. These substrates are poorly digested $(<30 \%$ digested $)$ in the small intestine, but are partially fermented by bacteria in the large bowel ${ }^{(2,3)}$. Therefore, PDX and SCF can be considered dietary fibres; however, more information is needed on the health effects of these substrates. These functional carbohydrates are known to be water-soluble and have many properties similar to dietary fibres. Specifically, PDX has been reported to increase faecal bulk, soften stools and lower faecal $\mathrm{pH}$ due to its partial fermentability in the large bowel ${ }^{(4-6)}$. Soluble maize fibre has been found to increase SCFA production and beneficial bacteria concentrations, while decreasing endproducts of protein fermentation in vitro ${ }^{(7)}$; however, limited data are available in vivo. Determining in vivo characteristics of these fibres and their impact on gastrointestinal tolerance are important to determine their efficacy as supplemental fibres.

Abbreviations: BCFA, branched-chain fatty acids; NFC, no supplemental fibre control; PDX, polydextrose; qPCR, quantitative PCR; SCF, soluble maize fibre. 
Beyond the expected effects of dietary fibres, soluble fibres such as PDX and SCF also may act as prebiotics. A prebiotic is a non-digestible food ingredient that beneficially affects the host by stimulating the growth or activity of specific species of bacteria in the hindgut, which are thought to improve gut health ${ }^{(8)}$. Prebiotics increase the numbers of potentially beneficial bacterial species (for example, bifidobacteria and lactobacilli) ${ }^{(9)}$, while decreasing potentially pathogenic bacteria (for example, Clostridium perfringens and Escherichia coli). Pathogenic bacteria are controlled due to decreasing $\mathrm{pH}$ resulting from the increased production of SCFA and increased competition for nutrients ${ }^{(10)}$.

The objective of the present study was to determine utilisation of two functional soluble fibres, PDX and SCF, in comparison with no supplemental fibre (no fibre control; NFC). This was determined by measuring: total faecal weights and laxation; faecal $\mathrm{pH}$; faecal fermentative endproducts including ammonia, phenol, indole, SCFA and branched-chain fatty acids (BCFA); and quantification of specific bacterial species. Additionally, subjective scoring of gastrointestinal tolerance (burping, cramping, distension, flatulence, nausea, reflux and vomiting), stool characteristics (faecal score) and ease of stool passage were determined.

\section{Materials and methods}

\section{Subjects}

Healthy adult men ( $n$ 25) with an average daily intake of dietary fibre of approximately $13-15 \mathrm{~g}$ were recruited for this experiment. Subjects were recruited via an email list server from the College of Agricultural, Consumer and Environmental Sciences at the University of Illinois. Entrance demographics and vital signs were collected for all subjects to ensure general health. Of the twenty-one subjects who completed the study, thirteen were self-described as Latino, eight as Caucasian, two as Asian, one as African-American and one as East Indian. All subjects were free of antibiotics for at least 3 months before study initiation. Before initiation of the experiment, the protocol and informed consent form were approved by the University of Illinois Institutional Review Board.

To be eligible for the experiment, all subjects had to meet the following criteria: (1) be between 20 and 40 years of age; (2) be free of known metabolic and gastrointestinal diseases, with no history of metabolic or gastrointestinal diseases; (3) avoid taking medications that would have an impact on bowel function; (4) refrain from consuming pre- or probiotic supplements during the entire duration of the study; (5) limit their alcohol consumption to two servings per $d$; (6) agree to avoid any changes in chronic medications until the end of the study; (7) agree to maintain the same dosage of any mineral and vitamin supplements consumed until completion of the study; (8) maintain their current level of exercise and physical activity; (9) be willing to complete all necessary study questionnaires and to donate stool specimens as required; (10) consume a moderate-fibre diet (12-13g fibre per d); and (11) voluntarily sign a written informed consent form before participation in the study.

\section{Experimental design and treatments}

A tolerance trial was conducted before the start of the present study evaluating PDX and SCF (7, 14 or $21 \mathrm{~g} / \mathrm{d}$ ) in the study population. Each fibre source was tested independently in a completely randomised design. In each group, seven subjects were asked to consume the varying fibre doses and record daily gastrointestinal tolerance and faecal description scores. Due to lack of differences in gastrointestinal tolerance subjective scores, it was decided to test the substrates at $21 \mathrm{~g} / \mathrm{d}$ for the following study due to only limited increases in negative gastrointestinal tolerance scores among the subjects. Therefore, during the utilisation portion of the study, subjects were asked to consume three treatment bars per $d$ corresponding with each meal (breakfast, lunch and dinner) for a total of $0 \mathrm{~g}$ (NFC) or $21 \mathrm{~g}$ PDX and $21 \mathrm{~g}$ SCF of supplemental fibre per $\mathrm{d}$.

Subjects were enrolled in a randomised, double-blind, placebo-controlled cross-over study. Subjects were randomly assigned one of two fibre sources or no supplemental fibre during each period in a Latin-square design. There was no washout time between periods. The present study consisted of three periods lasting $21 \mathrm{~d}$, with $16 \mathrm{~d}$ adaptation followed by $5 \mathrm{~d}$ of total faecal collections. Treatments included NFC (no supplemental fibre control), PDX (Litesse II ${ }^{\circledR}$; Danisco, Copenhagen, Denmark) and SCF (PROMITOR ${ }^{\mathrm{TM}}$; Tate \& Lyle Ingredients, Decatur, IL, USA). Litesse $\mathrm{II}^{\circledR} \mathrm{PDX}$ is a low-glycaemic functional fibre that contains $1 \mathrm{kcal} / \mathrm{g}$ (about $4 \mathrm{~kJ} / \mathrm{g}$ ) of substrate. Promitor ${ }^{\circledR}$ SCF contains $70 \%$ total dietary fibre and contains $2 \mathrm{kcal} / \mathrm{g}$ (about $8 \mathrm{~kJ} / \mathrm{g}$ ) of substrate. The fibre was provided in a snack bar made of rice crisps and manufactured by General Mills, Inc. (Minneapolis, MN, USA). Each snack bar contained approximately $7 \mathrm{~g}$ supplemental fibre or $0 \mathrm{~g}$ fibre (NFC).

The test bars were analysed for moisture, total fat, protein and water activity ${ }^{(11,12)}$. Total dietary fibre was determined and insoluble and soluble fractions determined. Resistant oligosaccharides and resistant oligosaccharides from fructans were determined according to Association of Official Analytical Chemists (AOAC) methods. Carbohydrates were then determined by difference.

\section{Diet and stool records}

Subjects were required to maintain daily diet and stool records throughout the entire study. The amount and type of all foods or liquids consumed in each $24 \mathrm{~h}$ period were recorded. Diet records were processed using the ESHA Food Processor SQL computer software program version 10.7.0 (ESHA Research, Salem, OR, USA). Dietary energy, protein, fat, fibre and carbohydrate intakes were calculated from the dietary records.

Subjects recorded the date, time, consistency and ease of passage of each bowel movement. Stool consistency was scored as follows: $1=$ hard, dry pellets - small, hard mass; $2=$ hard, formed, dry stool - remains firm and soft; $3=$ soft, formed, moist - softer stool that retains shape; $4=$ soft, unformed stool assumes shape of container; and 5= watery - liquid that can be poured. Ease of stool passage also was ranked on 
a five-point scale $(1=$ very easy, $2=$ easy, $3=$ neither easy nor difficult, $4=$ difficult, $5=$ very difficult). Subjects also ranked on a four-point scale $(1=$ none, $2=$ mild, $3=$ moderate, $4=$ severe) the following subjective tolerance variables daily: burping, cramping, distension/bloating, flatulence, nausea, reflux (heartburn) and vomiting.

\section{Stool collection and analysis}

Total faeces were collected over the last $5 \mathrm{~d}$ of each period. An attempt was made to collect three fresh stool specimens during each collection period to account for daily variation. Samples were collected using Commode Specimen Collection Systems (Sage Products, Crystal Lake, IL, USA) and fresh samples were brought to the laboratory within $15 \mathrm{~min}$ of defecation, while all other samples were brought to the laboratory within $1 \mathrm{~h}$ or early the next morning; participants were asked to refrigerate these samples. Total faecal weight was measured using both the $5 \mathrm{~d}$ total weight and the last $4 \mathrm{~d}$ of faecal collection. Both values were reported due to some subjects forgetting to collect a faecal sample during the first day of the first period.

All stool samples were weighed upon arrival at the laboratory. A sample for DM analysis was obtained. Fresh samples were further processed by taking a $\mathrm{pH}$ measurement and a sample was removed for bacterial DNA extraction. The remainder of the fresh sample was then frozen at $-20^{\circ} \mathrm{C}$ and stored until the three fresh samples were obtained. Upon collection of all three fresh faecal samples from each individual, the samples were thawed and composited using manual stirring. Samples then were taken for SCFA, BCFA, ammonia, phenol and indole concentrations, and stored at $-20^{\circ} \mathrm{C}$ until analysed. The ammonia, SCFA and BCFA sample ( $5 \mathrm{~g}$ ) was acidified with $5 \mathrm{ml}$ of $2 \mathrm{M}-\mathrm{HCl}$ before refreezing.

Faecal DM was measured according to the Association of Official Analytical Chemists ${ }^{(13)}$. Faecal $\mathrm{pH}$ was obtained using a Denver Instrument $\mathrm{AP} 10 \mathrm{pH}$ meter (Denver Instrument, Bohemia, NY, USA) equipped with a Beckman electrode (Beckman Instruments, Inc., Fullerton, CA, USA). Ammonia concentrations were measured according to the method of Chaney \& Marbach ${ }^{(14)}$. GC was used to measure SCFA according to Erwin et al. ${ }^{(15)}$. Briefly, acetate, propionate, butyrate, isobutyrate, isovalerate and valerate concentrations were determined on the supernatant fraction of acidified faecal samples using a Hewlett-Packard 5890A Series II gas chromatograph (Palo Alto, CA, USA) and a glass column $(180 \mathrm{~cm} \times 4 \mathrm{~mm}$ internal diameter) packed with $10 \%$ SP1200-1\% $\mathrm{H}_{3} \mathrm{PO}_{4}$ on $80 / 100+$ mesh Chromosorb WAW (Supelco, Bellefonte, PA, USA). $\mathrm{N}_{2}$ was the carrier gas with a flow rate of $75 \mathrm{ml} / \mathrm{min}$. Oven, detector and injector temperatures were 125,180 and $175^{\circ} \mathrm{C}$, respectively.

Additionally, subsamples of stools collected for microbiota analysis were stored at $-80^{\circ} \mathrm{C}$. Bacterial DNA was purified using QIAamp DNA stool mini kits (Qiagen, Valencia, CA, USA) using the repeated bead beating plus column $(\mathrm{RBB}+\mathrm{C})$ method described by $\mathrm{Yu} \&$ Morrison $^{(16)}$. Faecal
DNA was quantified using a NanoDrop ND-1000 spectrophotometer (NanoDrop Technologies, Wilmington, DE, USA).

\section{Quantitative $P C R$ analysis}

E. coli, Bifidobacterium genus and Lactobacillus genus were quantified via quantitative PCR using specific primers, as described in Hernot et al. ${ }^{(17)}$. Amplification was performed on a set of triplicate reactions for each bacterial group within each sample according to the procedures of Deplancke et $a{ }^{(18)}$. For amplification, $10 \mu \mathrm{l}$ final volume containing $2 \mathrm{X}$ SYBR Green PCR Master Mix (Applied BioSystems, Foster City, CA, USA), $15 \mathrm{pmol}$ of each primer and $5 \mathrm{ng}$ of template DNA was used. Pure cultures of each bacterium were utilised to create a five-fold dilution series $\left(10 \times 10^{0}\right.$ to $\left.10 \times 10^{5}\right)$ in triplicate from target species ${ }^{(19)}$. DNA from each serial dilution was amplified along with faecal DNA samples using a Taqman ABI PRISM 7900HT Sequence Detection System (Applied BioSystems). The colony-forming units of each standard curve serial dilution was previously determined by plating the $E$. coli grown on Luria-Bertani (LB) medium (tryptose $(10 \mathrm{~g} / \mathrm{l})$, yeast extract $(5 \mathrm{~g} / \mathrm{l}), \mathrm{NaCl}(5 \mathrm{~g} / \mathrm{l}) ; \mathrm{pH}=7)$, Lactobacillus genus on Difco Lactobacilli de Man-RogosaSharpe (MRS) broth (Becton, Dickenson and Co., Sparks, $\mathrm{MD}$, USA) and the Bifidobacterium genus on Difco Reinforced Clostridial Medium (Becton, Dickenson and Co.). Cycle threshold values were plotted against standard curves for quantification (colony-forming units per $g$ faeces) of the target bacterial DNA from faecal samples.

\section{Calculations and statistical analyses}

Data were analysed using the Mixed Models procedure of SAS (SAS Institute, Inc., Cary, NC, USA). The fixed effect of treatment was tested. Period and subject were considered random effects. Total dietary fibre consumed, as determined through diet records, was used as a covariate. Differences among treatments were determined using a Fisher-protected least significant difference with a Tukey adjustment to control for experiment-wise error. Non-continuous survey data were compared using the GLIMMIX procedure of SAS. These data were averaged by period. The fixed effect of treatment was tested. A probability of $P<0.05$ was accepted as statistically significant and a probability of $P<0.10$ was considered a trend. Reported pooled standard errors of the mean were determined according to the Mixed Models procedure of SAS.

\section{Results}

Of the twenty-five subjects enrolled, three were removed from the study before study initiation and one did not complete the study. Two (one Latino and one Asian) were dropped due to moving away, one (Caucasian) was dropped due to starting medication restricted by the study, and one (Latino) was dropped due to aberrant faecal patterns (greater than three watery stools per $d$ throughout the study) compared with the remainder of the study population (as determined during the initial tolerance study and before initiation of the 
Table 1. Physical characteristics of the experimental subjects

(Mean values, standard deviations and ranges)

\begin{tabular}{lrrl}
\hline & Mean & \multicolumn{1}{c}{ SD } & Range \\
\hline Age (years) & $27 \cdot 5$ & $4 \cdot 33$ & $21-28$ \\
Body weight $(\mathrm{kg})$ & $86 \cdot 2$ & $13 \cdot 48$ & $60-110$ \\
BMI (kg/m $\left.\mathrm{m}^{2}\right)$ & $27 \cdot 0$ & $4 \cdot 02$ & $20-34$ \\
Systolic blood pressure $(\mathrm{mmHg})$ & $124 \cdot 2$ & 14.46 & $99-148$ \\
Diastolic blood pressure $(\mathrm{mmHg})$ & $74 \cdot 6$ & $8 \cdot 28$ & $54-87$ \\
\hline
\end{tabular}

present study). The descriptions of the twenty-one subjects are listed in Table 1. Macronutrient intake for each treatment group is presented in Table 2. Macronutrient intake did not differ among treatment groups $(P>0.05)$.

Analysis of the test bars indicated that they were very similar in chemical composition (Table 3). Resistant oligosaccharides and total dietary fibre concentrations indicated that the treatment bars with functional fibres contained approximately $8 \mathrm{~g}$ fibre per bar (PDX $=8.06 \mathrm{~g} / \mathrm{bar}$; $\mathrm{SCF}=7.60 \mathrm{~g} / \mathrm{bar})$. After removal of the intrinsic fibre of the bar (1.0\%), the bars contained approximately $7.5 \mathrm{~g} / \mathrm{bar}$ (PDX $=7.64 \mathrm{~g} / \mathrm{bar}$; SCF $=7 \cdot 18 \mathrm{~g} / \mathrm{bar}$ ), which is close to the formulated value for these bars ( $7 \mathrm{~g} /$ bar).

The main effects of treatment for gastrointestinal tolerance, ease of stool passage and faecal scoring (stool consistency) are presented in Table 4. Flatulence $(P=0.001)$ and distention $(P=0.07)$ were greatest when subjects consumed PDX or SCF. Reflux was greater $(P=0 \cdot 04)$ when subjects consumed SCF compared with NFC. Ease of stool passage and stool consistency did not differ due to treatment.

Faecal fermentative endproducts are presented in Table 5. Faecal ammonia concentration was decreased $(P<0 \cdot 0001)$ when subjects consumed either of the functional fibres, but was lowest with PDX. Faecal 4-methylphenol, indole, and isobutyrate, isovalerate and total BCFA concentrations were decreased $(P<0 \cdot 01)$ when subjects consumed the functional fibre sources compared with NFC. Faecal valerate concentrations were lower $(P<0.005)$ when subjects consumed
PDX compared with NFC, with SCF intermediate. Faecal 2,3-methyl indole did not differ $(P=0.72)$ among treatments.

Faecal acetate, propionate and butyrate concentrations were lowest $(P<0.05)$ when subjects consumed PDX compared with SCF and NFC. Faecal SCFA molar ratios of acetate were higher $(P<0.0001)$ and ratios of butyrate lower $(P=0.005)$ when subjects consumed the PDX or SCF compared with NFC. Faecal propionate molar ratio tended to be lower $(P=0 \cdot 09)$ when subjects consumed PDX compared with NFC.

Faecal $\mathrm{pH}$ was lower $(P=0 \cdot 01)$ when subjects consumed SCF compared with NFC, while PDX was intermediate (Table 6). Faecal $5 \mathrm{~d}$ wet weight tended to be greater $(P=0.06)$ when subjects consumed SCF compared with NFC, while faecal $5 \mathrm{~d}$ dry weight was greater $(P=0 \cdot 02)$ when subjects consumed PDX or SCF compared with NFC. Faecal $4 \mathrm{~d}$ wet weight was greatest $(P=0.03)$ when subjects consumed SCF compared with NFC, with PDX intermediate. Faecal $4 \mathrm{~d}$ dry weight tended to be greater $(P=0 \cdot 07)$ when subjects consumed PDX compared with NFC. Average $(\mathrm{g} / \mathrm{d})$ faecal wet weight tended to be greater $(P=0.06)$ when subjects consumed SCF compared with NFC, while average faecal dry weight was greater $(P=0.02)$ when subjects consumed either supplemental fibre. The functional fibres led to 1.4 and $0.9 \mathrm{~g}$ (PDX and SCF, respectively) increases in faecal dry mass per $\mathrm{g}$ supplemental fibre intake. Number of defecations per period did not differ $(P=0.56)$ among treatments.

Faecal microbiota data are presented in Table 7. Bifidobacterium spp. were present in higher $(P<0.05)$ concentrations when subjects consumed SCF compared with NFC, while PDX was intermediate. Faecal Lactobacillus spp. and E. coli populations did not differ among treatments.

\section{Discussion}

The average dietary fibre intake in the USA is well below the recommended amount, $38 \mathrm{~g} / \mathrm{d}$ for an adult man ${ }^{(1)}$. Therefore, finding ways of increasing fibre consumption in the USA is of importance to aid colonic health. Adding non-digestible,

Table 2. Macronutrient intake of healthy adult men consuming no supplemental fibre (no fibre control; NFC), polydextrose (PDX; $21 \mathrm{~g} / \mathrm{d}$ ) or soluble maize fibre (SCF; $21 \mathrm{~g} / \mathrm{d}$ ) (Mean values with their pooled standard errors for twenty-one subjects)

\begin{tabular}{|c|c|c|c|c|c|}
\hline & \multicolumn{3}{|c|}{ Treatment } & \multirow[b]{2}{*}{ SEM } & \multirow[b]{2}{*}{$P$} \\
\hline & NFC & PDX & SCF & & \\
\hline Protein $(\mathrm{g} / \mathrm{d})$ & $91 \cdot 2$ & $89 \cdot 0$ & 89.6 & 5.02 & 0.95 \\
\hline Fat $(\mathrm{g} / \mathrm{d})$ & $76 \cdot 0$ & $70 \cdot 5$ & $79 \cdot 1$ & 5.35 & 0.51 \\
\hline Saturated fat $(\mathrm{g} / \mathrm{d})$ & 23.5 & 23.9 & $26 \cdot 1$ & 1.91 & 0.58 \\
\hline Carbohydrate $(\mathrm{g} / \mathrm{d})$ & 224.5 & 224.9 & 238.8 & $21 \cdot 30$ & 0.86 \\
\hline Total dietary fibre $(\mathrm{g} / \mathrm{d})^{*}$ & 14.8 & 14.8 & 14.4 & 1.23 & 0.97 \\
\hline \multicolumn{6}{|l|}{ Energy consumed } \\
\hline $\mathrm{kJ} / \mathrm{d}$ & $8192 \cdot 1$ & $8184 \cdot 2$ & $8330 \cdot 7$ & 589.69 & 0.98 \\
\hline $\mathrm{kcal} / \mathrm{d}$ & $1956 \cdot 6$ & 1954.8 & 1989.7 & 140.90 & 0.98 \\
\hline Protein (\% of energy) & $19 \cdot 2$ & $20 \cdot 1$ & 18.4 & 1.02 & 0.47 \\
\hline Fat (\% of energy) & $35 \cdot 4$ & 34.2 & $35 \cdot 0$ & 1.39 & 0.84 \\
\hline Carbohydrates ( $\%$ of energy) & $45 \cdot 5$ & $45 \cdot 6$ & $46 \cdot 6$ & 2.00 & 0.91 \\
\hline
\end{tabular}

* Total dietary fibre values reflect dietary fibre consumed in the normal diet of the subjects only; supplemental fibre is not included. 
Table 3. Composition of experimental fibre snack bars

\begin{tabular}{|c|c|c|c|}
\hline & \multicolumn{3}{|c|}{ Treatment } \\
\hline & NFC & PDX & SCF \\
\hline DM (\%) & $90 \cdot 97$ & $90 \cdot 77$ & 89.67 \\
\hline CP (\% DM) & 3.65 & 3.77 & 3.52 \\
\hline Fat (\% DM) & $7 \cdot 66$ & 4.37 & 5.09 \\
\hline Carbohydrates (\% DM) & $78 \cdot 60$ & $81 \cdot 70$ & $80 \cdot 00$ \\
\hline TDF (\% DM) & 0.90 & 0.60 & 1.40 \\
\hline Insoluble TDF (\% DM) & 0.70 & 0.20 & 0.30 \\
\hline Soluble TDF (\% DM) & 0.20 & 0.40 & $1 \cdot 10$ \\
\hline $\mathrm{RO}(\% \mathrm{DM})$ & 0.1 & $18 \cdot 6$ & $16 \cdot 7$ \\
\hline $\mathrm{RO}+\mathrm{TDF}(\% \mathrm{DM})$ & $1 \cdot 0$ & $19 \cdot 2$ & $18 \cdot 1$ \\
\hline \multicolumn{4}{|l|}{ Gross energy } \\
\hline $\mathrm{kJ} / 100 \mathrm{~g}$ & 1665 & 1594 & 1590 \\
\hline $\mathrm{kcal} / 100 \mathrm{~g}$ & 398 & 381 & 380 \\
\hline Weight of individual bar* $(\mathrm{g})$ & 37 & 42 & 42 \\
\hline
\end{tabular}

NFC, no supplemental fibre control; PDX, polydextrose; SCF, soluble maize fibre; $\mathrm{CP}$, crude protein; TDF, total dietary fibre; RO, resistant oligosaccharides.

${ }^{*}$ Bars were manufactured to weigh as designated above for each treatment, $\pm 2 \mathrm{~g}$.

fermentable carbohydrate sources that act as dietary fibres and that can be added to new or existing food products is one way to potentially increase fibre consumption. Therefore, the objective of the present study was to evaluate digestive physiological outcomes elicited by functional fibres fed to healthy adult men. PDX and SCF were evaluated for effects on gastrointestinal tolerance, faecal BCFA and putrefactive compound concentrations, faecal SCFA concentrations, laxation and faecal microbiota populations.

Dietary fibre ingestion, even in relatively small amounts, can lead to gastrointestinal discomfort but varies widely among individuals. Therefore, before determining efficiency of PDX and SCF, a dose-response experiment with the same individuals that were enrolled in the main experiment was conducted. It was determined through subjective scoring that the subject population was able to consume as much as $21 \mathrm{~g}$ PDX or SCF per d with little gastrointestinal discomfort (Supplemental Tables 1-4, available online at http://www. journals.cambridge.org/bjn). Furthermore, this amount of supplemental fibre bridged the gap to the fibre requirement of adult men (average intake $15 \mathrm{~g} / \mathrm{d}$, recommended intake $38 \mathrm{~g} / \mathrm{d}$, fibre gap $23 \mathrm{~g} / \mathrm{d}$ ).

Overall, compliance was excellent throughout the study. All diet records were analysed and it was determined that the subjects consumed a moderate-fibre diet (average fibre intake, $14.7 \mathrm{~g} / \mathrm{d}$ ). Dietary macronutrient composition also remained steady over time, as it did not differ due to treatment. The final composition of the test bars provided close to the $7 \mathrm{~g} / \mathrm{bar}$ that was formulated. There was $1 \%$ intrinsic fibre in the test bars (NFC), with the PDX bar containing approximately $7.6 \mathrm{~g}$ fibre/bar and the SCF bar containing $7 \cdot 2 \mathrm{~g}$ fibre/bar after accounting for the intrinsic fibre present.

Excessive consumption of some fermentable carbohydrates has been reported to lead to gastrointestinal side effects such as bloating, abdominal cramps, flatulence and borborygmi, especially in sensitive individuals ${ }^{(20)}$. These symptoms are transient and cease or lessen when the fibre intake is reduced or stopped completely ${ }^{(2)}$. Supplemental PDX and SCF were well tolerated by all subjects, with only mild increases in distension, flatulence and reflux. Interestingly, although only moderately, the greatest amount of flatulence was noted by subjects consuming PDX. Jie et $a l^{(21)}$ noted no changes in gastrointestinal discomfort when subjects consumed as much as $12 \mathrm{~g} \mathrm{PDX/d}$. Furthermore, total gas production was lowest for PDX compared with other substrates when evaluated in vitro ${ }^{(17,22)}$; however, SCF was not tested in these experiments. Supplemental SCF consumed at $12 \mathrm{~g} / \mathrm{d}$ was noted to increase self-reported flatulence and stomach noise scores ${ }^{(3)}$. This increase in flatulence is similar to that noted in the present study. Stewart et $a l .{ }^{(3)}$ noted, on a tenpoint scale, flatulence scores of 4.2 in subjects consuming SCF $v \cdot 2 \cdot 8$ in subjects consuming a maltodextrin control treatment. It was noted, however, that all subjects tolerated the supplemental fibre sources well. Similarly, in the present study, average tolerance scores were low $(<2 \cdot 5)$, indicating only mild to moderate discomfort.

We saw no changes in subjective scoring of stool consistency. These results are in contrast with previous literature indicating that PDX leads to a softening of the stool ${ }^{(2,21)}$ and easier passage ${ }^{(19)}$. A softening of stools was not noted by Stewart et al. ${ }^{(3)}$, however, when subjects consumed $12 \mathrm{~g}$ $\mathrm{SCF} / \mathrm{d}$. It should be noted that results from the present study were self-reported scores by the subjects; differences in objective measures of faecal weight and moisture content were noted.

Ammonia, phenol, indoles and BCFA (isobutyrate, isovalerate and valerate) are products of protein fermentation by gut microbiota. These putrefactive compounds are linked to bowel cancer and can damage the colonic epithelium and become tumour growth promoters ${ }^{(23-25)}$. Decreases in faecal

Table 4. Gastrointestinal tolerance scores and stool characteristic subjective scores during the entire treatment period for healthy adult men consuming no supplemental fibre (no fibre control; NFC), polydextrose (PDX; $21 \mathrm{~g} / \mathrm{d}$ ) or soluble maize fibre (SCF; $21 \mathrm{~g} / \mathrm{d}$ )

(Mean values with their pooled standard errors for twenty-one subjects)

\begin{tabular}{llllll}
\hline & \multicolumn{3}{c}{ Treatment } & & \\
\cline { 2 - 4 } & NFC & PDX & SCF & SEM & $P$ \\
\hline Gastrointestinal tolerance* & & & & & \\
$\quad$ Burping & 1.24 & 1.28 & 1.26 & 0.085 & 0.57 \\
Cramping & 1.11 & 1.20 & 1.15 & 0.068 & 0.12 \\
Distension & $1.33^{\mathrm{x}}$ & $1.52^{\mathrm{y}}$ & $1.45^{\mathrm{x}, \mathrm{y}}$ & 0.120 & 0.07 \\
Flatulence & $1.83^{\mathrm{a}}$ & $2.23^{\mathrm{b}}$ & $2.08^{\mathrm{b}}$ & 0.099 & 0.001 \\
Nausea & 1.00 & 1.00 & 1.01 & 0.004 & 0.24 \\
Reflux & $1.03^{\mathrm{a}}$ & $1.03^{\mathrm{a}, \mathrm{b}}$ & $1.08^{\mathrm{b}}$ & 0.021 & 0.04 \\
$\quad$ Vomiting & 1.00 & 1.00 & 1.00 & 0.001 & 0.37 \\
Ease of stool passage† & 2.60 & 2.52 & 2.58 & 0.097 & 0.83 \\
Stool consistency & 2.93 & 3.06 & 2.99 & 0.070 & 0.41 \\
\hline
\end{tabular}

${ }^{\mathrm{a}, \mathrm{b}}$ Mean values within a row with unlike superscript letters were significantly different $(P<0.05)$.

${ }^{x, y}$ Mean values within a row with unlike superscript letters tended to differ $(P<0 \cdot 10)$.

* Gastrointestinal tolerance was scored using the following scale: $1=$ none, $2=$ mild, $3=$ moderate, $4=$ severe.

† Ease of stool passage was scored using the following scale: $1=$ very easy, $2=$ easy, $3=$ neither easy nor difficult, $4=$ difficult, $5=$ very difficult.

¥ Stool consistency was scored using the following scale: $1=$ hard, dry pellets small, hard mass; 2 = hard, formed, dry stool - remains firm and soft; $3=$ soft, formed, moist - softer stool that retains shape; $4=$ soft, unformed - stool assumes shape of container; $5=$ watery - liquid that can be poured. 
Table 5. Faecal fermentative endproducts of healthy adult men consuming no supplemental fibre (no fibre control; NFC), polydextrose (PDX; $21 \mathrm{~g} / \mathrm{d}$ ) or soluble maize fibre (SCF; $21 \mathrm{~g} / \mathrm{d})$

(Mean values with their pooled standard errors for twenty-one subjects)

\begin{tabular}{|c|c|c|c|c|c|}
\hline & \multicolumn{3}{|c|}{ Treatment } & \multirow[b]{2}{*}{ SEM } & \multirow[b]{2}{*}{$P$} \\
\hline & NFC & PDX & SCF & & \\
\hline \multicolumn{6}{|c|}{ Endproduct ( $\mu \mathrm{mol} / \mathrm{g}$ DM faeces) } \\
\hline Ammonia & $137.5^{\mathrm{c}}$ & $97 \cdot 5^{\mathrm{a}}$ & $117 \cdot 0^{\mathrm{b}}$ & 7.82 & $<0.0001$ \\
\hline 4-Methyl phenol & $1.5^{b}$ & $0.6^{\mathrm{a}}$ & $0.9^{\mathrm{a}}$ & 0.20 & 0.003 \\
\hline 2,3-Methyl indole & 0.3 & 0.3 & 0.3 & 0.11 & 0.72 \\
\hline Indole & $1.0^{\mathrm{b}}$ & $0.3^{\mathrm{a}}$ & $0.5^{\mathrm{a}}$ & 0.17 & 0.003 \\
\hline Isobutyrate & $9 \cdot 1^{b}$ & $5 \cdot 3^{a}$ & $6 \cdot 5^{\mathrm{a}}$ & 0.88 & $<0.0001$ \\
\hline Isovalerate & $10 \cdot 4^{b}$ & $5 \cdot 7^{\mathrm{a}}$ & $6 \cdot 9^{\mathrm{a}}$ & 0.99 & $<0.0001$ \\
\hline Valerate & $10 \cdot 7^{b}$ & $7 \cdot 6^{\mathrm{a}}$ & $9 \cdot 0^{a, b}$ & $1 \cdot 17$ & 0.005 \\
\hline Total BCFA & $30 \cdot 3^{b}$ & $18 \cdot 6^{\mathrm{a}}$ & $22 \cdot 4^{\mathrm{a}}$ & $2 \cdot 76$ & $<0.0001$ \\
\hline Acetate & $320 \cdot 3^{\mathrm{a}, \mathrm{b}}$ & $272 \cdot 3^{\mathrm{a}}$ & $351 \cdot 6^{b}$ & 24.95 & 0.02 \\
\hline Propionate & $97 \cdot 3^{\mathrm{b}}$ & $74 \cdot 0^{\mathrm{a}}$ & $101 \cdot 6^{\mathrm{b}}$ & $10 \cdot 48$ & 0.008 \\
\hline Butyrate & $93 \cdot 8^{\mathrm{b}}$ & $60 \cdot 5^{\mathrm{a}}$ & $81 \cdot 0^{\mathrm{a}, \mathrm{b}}$ & $9 \cdot 13$ & 0.005 \\
\hline Total SCFA & $511 \cdot 4^{a, b}$ & $407 \cdot 0^{\mathrm{a}}$ & $534 \cdot 0^{\mathrm{b}}$ & 41.96 & 0.018 \\
\hline \multicolumn{6}{|l|}{ Ratio } \\
\hline Acetate & $0.63^{\mathrm{a}}$ & $0.68^{b}$ & $0.67^{b}$ & 0.01 & $<0.0001$ \\
\hline Propionate & $0 \cdot 19^{\mathrm{x}}$ & $0 \cdot 18^{y}$ & $0 \cdot 19^{x, y}$ & 0.01 & 0.097 \\
\hline Butyrate & $0 \cdot 18^{b}$ & $0 \cdot 15^{a}$ & $0 \cdot 15^{\mathrm{a}}$ & 0.006 & 0.005 \\
\hline
\end{tabular}

BCFA concentrations and ammonia are considered beneficial. Also, with increased stool production, there is a dilution effect, thereby potentially allowing less of the putrefactive compounds to come in contact with the intestinal epithelium. In the present study, supplemental fibre decreased all of the putrefactive compounds measured.

Lower concentrations of putrefactive compounds as a result of fibre ingestion have been reported previously. Pigs fed $30 \mathrm{~g}$ $\mathrm{PDX} / \mathrm{d}$ had decreased BCFA concentrations in the distal colon $^{(26)}$. Given that, in the present study, faecal BCFA were measured, distal colon values should be comparable with faecal values. Furthermore, it is the distal colon where carbohydrate is limiting and where protein is used as a fuel source for the microbiota. No effects were noted in ammonia concentrations when supplemental PDX was fed to pigs ${ }^{(26)}$. Indole, $p$-cresol, isovalerate and isobutyrate also were noted to decrease in human subjects fed a high-cholesterol diet with added $\mathrm{PDX}^{(5)}$, and isobutyrate and isovalerate decreased in healthy adults consuming $8 \mathrm{~g} \mathrm{PDX} / \mathrm{d}^{(27)}$. PDX also decreased total BCFA in vitro ${ }^{(28)}$. Jie et al. ${ }^{(21)}$ reported increased faecal isobutyrate concentrations when adult subjects consumed 8 or $12 \mathrm{~g} \mathrm{PDX} / \mathrm{d}$. It is unclear why an increase was noted in that study as compared with the other literature. Soluble maize fibre decreased isobutyrate, isovalerate and ammonia production in vitro ${ }^{(7)}$, which is consistent with the results of the present study.

Providing fermentable, non-digestible carbohydrates in a diet provides carbohydrate for the colonic microbiota. In the present study, we did not observe an increase in faecal SCFA, as would be expected, but rather a decrease when

Table 6. Faecal $\mathrm{pH}$, weight and mass increase per $\mathrm{g}$ for fibre intake of healthy adult men consuming no supplemental fibre (no fibre control; NFC), polydextrose (PDX; $21 \mathrm{~g} / \mathrm{d}$ ) or soluble maize fibre (SCF; $21 \mathrm{~g} / \mathrm{d}$ )

(Mean values with their pooled standard errors for twenty-one subjects)

\begin{tabular}{|c|c|c|c|c|c|}
\hline & \multicolumn{3}{|c|}{ Treatment } & \multirow[b]{2}{*}{ SEM } & \multirow[b]{2}{*}{$P$} \\
\hline & NFC & PDX & SCF & & \\
\hline $\mathrm{pH}$ & $6 \cdot 4^{a}$ & $6 \cdot 3^{a, b}$ & $6 \cdot 2^{b}$ & 0.14 & 0.01 \\
\hline Number of defecations per period & 23.9 & $25 \cdot 2$ & $25 \cdot 1$ & 2.59 & 0.56 \\
\hline Faecal $5 \mathrm{~d}$ wet weight $(\mathrm{g})$ & $735 \cdot 2^{x}$ & $809 \cdot 0^{x, y}$ & $881 \cdot 3^{y}$ & 64.84 & 0.06 \\
\hline Faecal 5 d DM weight $(\mathrm{g})$ & $155 \cdot 9^{a}$ & $184 \cdot 8^{\mathrm{b}}$ & $187 \cdot 9^{\mathrm{b}}$ & 11.81 & 0.02 \\
\hline Faecal $4 \mathrm{~d}$ wet weight $(\mathrm{g})$ & $593 \cdot 7^{a}$ & $693 \cdot 0^{\mathrm{a}, \mathrm{b}}$ & $748 \cdot 8^{\mathrm{b}}$ & 58.92 & 0.03 \\
\hline Faecal 4 d DM weight (g) & $129 \cdot 2^{x}$ & $158 \cdot 3^{y}$ & $147 \cdot 8^{x, y}$ & $11 \cdot 11$ & 0.07 \\
\hline Faecal 4 d wet weight (g/d) & $184 \cdot 1^{x}$ & $202 \cdot 3^{x, y}$ & $220 \cdot 3^{y}$ & $16 \cdot 21$ & 0.06 \\
\hline Faecal 4 d DM weight (g/d) & $39 \cdot 0^{\mathrm{a}}$ & $46 \cdot 2^{b}$ & $47 \cdot 0^{b}$ & 2.95 & 0.02 \\
\hline Faecal mass per g fibre intake, as-is & - & $4 \cdot 3$ & $7 \cdot 7$ & 2.47 & 0.27 \\
\hline Faecal mass per g fibre intake, DM & - & 1.4 & 0.9 & 0.54 & 0.54 \\
\hline
\end{tabular}

${ }^{a, b}$ Mean values within a row with unlike superscript letters were significantly different $(P<0.05)$.

${ }^{\mathrm{x}, \mathrm{y}}$ Mean values within a row with unlike superscript letters tended to differ $(P<0 \cdot 10)$. 
Table 7. Faecal microbiota (log colony-forming units/g DM faeces) of healthy adult men consuming no supplemental fibre (no fibre control; NFC), polydextrose (PDX; $21 \mathrm{~g} / \mathrm{d}$ ) or soluble maize fibre (SCF; $21 \mathrm{~g} / \mathrm{d}$ )

(Mean values with their pooled standard errors for twenty-one subjects)

\begin{tabular}{lrrrrr}
\hline & \multicolumn{3}{c}{ Treatment } & & \\
\cline { 2 - 4 } & NFC & PDX & SCF & SEM & $P$ \\
\hline Bifidobacterium spp. & $6.9^{\mathrm{a}}$ & $7.7^{\mathrm{a}, \mathrm{b}}$ & $8.2^{\mathrm{b}}$ & 0.61 & 0.03 \\
Lactobacillus spp. & 10.1 & 10.1 & 10.5 & 0.69 & 0.64 \\
Escherichia coli & 8.9 & 8.6 & 9.5 & 0.47 & 0.22
\end{tabular}

${ }^{\mathrm{a}, \mathrm{b}}$ Mean values within a row with unlike superscript letters were significantly different $(P<0.05)$.

PDX was consumed, and no change between the NFC and SCF treatments. In vitro fermentation of fibres with the addition of PDX also reduced SCFA production compared with the substrates alone ${ }^{(22)}$. Furthermore, PDX fermented alone had the lowest SCFA production when compared with other fibre sources tested ${ }^{(17,22)}$. Similar to the results of the present study, proximal, middle and distal colonic digesta samples from pigs fed $30 \mathrm{~g}$ PDX/d had numerically lower SCFA concentrations (acetate, propionate and butyrate) ${ }^{(26)}$. In the distal colon, as to faecal concentrations, both propionate and butyrate concentrations were statistically lower in pigs fed PDX. Again, in contrast to the reported literature, Jie et $a l .{ }^{(21)}$ noted greater faecal acetate and butyrate production when subjects consumed 8 or $12 \mathrm{~g} \mathrm{PDX} / \mathrm{d}$ as compared with subject baseline values.

The lack of SCFA differences between the SCF and NFC groups may be due to the increase in stool volume when subjects consumed the SCF, thereby leading to a dilution of SCFA in the faeces. A similar response was noted by Weaver et al. ${ }^{(29)}$ in rats. When comparing faecal SCFA concentrations, only propionate had a greater concentration compared with the control group; however, caecal content weight was greater when rats consumed SCF compared with the control diet. Therefore, when SCFA were expressed on a total caecal contents basis, acetate, propionate and total SCFA amounts were greater in rats fed SCF compared with control ${ }^{(29)}$. A study in human subjects noted similar results to those of the present study, with no difference in faecal total SCFA concentrations of human subjects fed $12 \mathrm{~g}$ SCF/d compared with the control $^{(3)}$. Neither of these functional fibres appeared to be butyrogenic, and limited fermentation was noted compared with that of the NFC group. Other literature supports the lack of an increase in faecal butyrate with PDX or SCF supplementation $^{(3,26,29)}$. Faecal SCFA concentrations were similar to those reported in previous research evaluating human subjects consuming a resistant maltodextrin ${ }^{(30)}$.

Faecal SCFA molar ratios were similar to those reported by Fastinger et $a l{ }^{(30)}$, but the molar ratio of acetate was greater in the present study compared with that reported in previous research evaluating $\mathrm{SCF}^{(3)}$. In that study, the SCFA molar ratios ( 0.43 acetate, 0.26 propionate and 0.31 butyrate) did not differ between control (maltodextrin) and SCF treatments. This indicates that the difference between the present results and those of Stewart et al. ${ }^{(3)}$ is probably due to the subject population, dietary patterns of the subjects or the analytical procedures used.

The decrease in $\mathrm{pH}$ was minimal, but consistent with previous research with human subjects consuming $12 \mathrm{~g}$ PDX/ $\mathrm{d}^{(21)}$. While the supplemental fibres did not increase the number of defecations per $\mathrm{d}$, they led to an increase in stool volume, indicating a laxation effect. This is similar to results from other reports of PDX ingestion by human subjects ${ }^{(5,6)}$, and greater caecal content weights with PDX and SCF supplementation of rats $^{(28)}$. No change in stool weight was noted when subjects were supplemented with $8 \mathrm{~g} \mathrm{PDX} / \mathrm{d}$, but the authors noted an increase in orofaecal transit time when subjects consumed $\mathrm{PDX}^{(27)}$. Although both total $5 \mathrm{~d}$ and $4 \mathrm{~d}$ total faecal collection values are provided, the $4 \mathrm{~d}$ total faecal weights are a more accurate measure of faecal mass due to subject error during the initial collection day of the first period.

The present results indicate that both PDX and SCF consumed at $21 \mathrm{~g} / \mathrm{d}$ may have a prebiotic effect in healthy adult men, as both led to an approximate $1 \mathrm{log}$ increase in Bifidobacterium spp., with the greatest effect being noted for SCF. Data regarding the prebiotic effect of PDX are mixed. Bifidobacteria populations were not changed with PDX supplementation of pigs ${ }^{(26)}$ or human subjects ${ }^{(5)}$. Interestingly, in pigs, bifidobacteria populations decreased numerically compared with the control treatment ${ }^{(26)}$. Bifidobacteria populations were high in comparison with baseline data in the present study, 9.7-10.1 $\log _{10}$ per g wet faeces ${ }^{(5)}$, which may have masked any effects of PDX on these populations. Similar to results of the present study, PDX at 4,8 or $12 \mathrm{~g} / \mathrm{d}$ led to increases in faecal bifidobacteria ${ }^{(21)}$. A $1 \mathrm{log}$ unit change was noted after supplementation with $12 \mathrm{~g}$ $\mathrm{PDX} / \mathrm{d}^{(21)}$; we noted a similar response with $21 \mathrm{~g} \mathrm{PDX} / \mathrm{d}$ supplementation. PDX also is reported to lead to increases in bifidobacteria in vitro ${ }^{(17,22,31)}$. There is limited literature regarding the utilisation of SCF, and only one study in the literature to date evaluating microbiota. Total bifidobacteria species populations were greater for SCF over time when analysed semi-quantitatively in vitro, with $B$. adolescentis and $B$. bifidum being increased the greatest ${ }^{(7)}$. Given the magnitude of change in Bifidobacterium spp. (1.3 log units) when subjects consumed SCF in the present study, further investigation into its prebiotic potential is warranted.

Overall, these data are consistent with previous reports that PDX and SCF are fermentable fibres and may be beneficial to colonic health. The effects noted in the present study, including reduction in faecal putrefactive compounds, stool bulking and bifidogenic potential, indicate that these functional fibres exert positive health effects in humans. Furthermore, these supplemental fibres, even at relatively large dosages $(21 \mathrm{~g} / \mathrm{d})$, minimally increased gastrointestinal tolerance scores, indicating only slight discomfort in the present study population, while still providing a highly acceptable snack bar product. Therefore, PDX and SCF may be good candidates as supplemental fibre sources in food products for humans. 


\section{Acknowledgements}

The present study was supported by General Mills, Inc.

B. M. V. B., T. W. B., K. S. S. and G. C. F. designed the research; B. M. V. B., M. C. R. S. and L. L. B. conducted the research; B. M. V. B. analysed the data; M. S. and T. W. B. provided essential materials for this research; B. M. V. B. wrote the manuscript; and G. C. F. had primary responsibility for the final content. All authors read and approved the final manuscript.

M. S. and T. W. B. work for General Mills, Inc. who provided funding for the study. B. M. V. B., M. C. R. S., L. L. B., K. S. S. and G. C. F. have no conflicts of interest.

\section{References}

1. Institute of Medicine (2005) Dietary Reference Intakes for Energy, Carbohydrates, Fiber, Fat, Fatty Acids, Cholesterol, Protein, and Amino Acids. Washington, DC: National Academies Press.

2. Flood MT, Auerbach MH \& Craig SAS (2004) A review of the clinical toleration studies of polydextrose in food. Food Chem Toxicol 42, 1531-1542.

3. Stewart ML, Nikhanj SD, Timm DA, et al. (2010) Evaluation of the effects of four fibers on laxation, gastrointestinal tolerance, and serum markers in healthy humans. Ann Nutr Metab 56, 91-98.

4. Nakagawa Y, Okamatsu H \& Fujii Y (1990) Effects of polydextrose feeding on the frequency and feeling of defecation in healthy adult female volunteers. JJpn Soc Nutr Food Sci 43, 95-101.

5. Endo K, Kumemura M, Nakamura K, et al. (1991) Effect of high cholesterol diet and polydextrose supplementation on the microflora, bacterial enzyme activity, putrefactive products, volatile fatty acid (VFA) profile, weight, and $\mathrm{pH}$ of the feces in healthy volunteers. Bifidobact Microflora 10, 53-64.

6. Achour L, Flourie B, Briet F, et al. (1994) Gastrointestinal effects and energy value of polydextrose in healthy, nonobese men. Am J Clin Nutr 59, 1362-1368.

7. Maathuis A, Hoffman A, Evans A, et al. (2009) The effect of the undigested fraction of maize products on the activity and composition of the microbiota determined in a dynamic in vitro model of the human proximal large intestine. $J \mathrm{Am}$ Coll Nutr 28, 657-666.

8. Gibson GR \& Roberfroid MB (1995) Dietary modulation of human colonic microbiota: introducing the concept of prebiotics. J Nutr 125, 1401-1412.

9. Buddington RK (2001) The use of nondigestible oligosaccharides to manage the gastrointestinal ecosystem. Micro Ecol Health Dis 13, 9-15.

10. Fuller R \& Gibson GR (1997) Modification of the intestinal microflora using probiotics and prebiotics. Scand J Gasteroenterol Suppl 222, 28-31.

11. Association of Official Analytical Chemists (2005) Official Methods of Analysis, 18th ed. Washington, DC: AOAC.

12. American Association of Cereal Chemists (1983) Approved Methods, 8th ed. St Paul: AACC.

13. Association of Official Analytical Chemists (1984) Official Methods of Analysis, 14th ed. Washington, DC: AOAC.
14. Chaney AL \& Marbach EP (1962) Modified reagents for determination of urea and ammonia. Clin Chem 8, 130-132.

15. Erwin ES, Marco GJ \& Emery EM (1961) Volatile fatty acid analyses of blood and rumen fluid by gas chromatography. J Dairy Sci 44, 1768-1771.

16. Yu Z \& Morrison M (2004) Improved extraction of PCRquality community DNA from digesta and fecal samples. BioTechniques 36, 808-812.

17. Hernot DC, Boileau TW, Bauer LL, et al. (2009) In vitro fermentation profiles, gas production rates, and microbiota modulation as affected by certain fructans, galactooligosaccharides, and polydextrose. I Agric Food Chem 57, $1354-1361$.

18. Deplancke B, Vidal O, Ganessunker D, et al. (2002) Selective growth of mucolytic bacteria including Clostridium perfringens in a neonatal piglet model of total parenteral nutrition. Am J Clin Nutr 76, 1117-1125.

19. Middelbos IS, Godoy MR, Fastinger ND, et al. (2007) A dose-response evaluation of spray-dried yeast cell wall supplementation of diets fed to adult dogs: effects on nutrient digestibility, immune indices, and fecal microbial populations. J Anim Sci 85, 3022-3032.

20. Sandler RS, Stewart WF, Liberman JN, et al. (2000) Abdominal pain, bloating, and diarrhea in the United States: prevalence and impact. Digest Dis Sci 45, 1242-1254.

21. Jie Z, Bang-yao L, Ming-jie X, et al. (2000) Studies on the effects of polydextrose intake on physiologic functions in Chinese people. Am J Clin Nutr 72, 1503-1509.

22. Vester Boler BM, Hernot DC, Boileau TW, et al. (2009) Carbohydrates blended with polydextrose lower gas production and short-chain fatty acid production in an in vitro system. Nutr Res 29, 631-639.

23. Bone E, Tamm A \& Hill M (1976) The production of urinary phenols by gut bacteria and their possible role in the causation of large bowel cancer. Am J Clin Nutr 29, 1448-1454.

24. Visek WJ (1978) Diet and cell growth modulation by ammonia. Am J Clin Nutr 31, S216-S220.

25. Bingham SA (1988) Meat, starch, and nonstarch polysaccharides and large bowel cancer. Am J Clin Nutr 48, 762-767.

26. Fava F, Mäkivuokko H, Siljander-Rasi H, et al. (2007) Effect of polydextrose on intestinal microbes and immune functions in pigs. Br J Nutr 98, 123-133.

27. Hengst C, Ptok S, Roessler A, et al. (2009) Effects of polydextrose supplementation on different faecal parameters in healthy volunteers. Int J Food Sci Nutr 60, 96-105.

28. Mäkivuokko H, Kettunen H, Saarinen M, et al. (2007) The effects of cocoa and polydextrose on bacterial fermentation in gastrointestinal tract simulations. Biosci Biotechnol Biochem 71, 1834-1843.

29. Weaver CM, Martin BR, Story JA, et al. (2010) Novel fibers increase bone calcium content and strength beyond efficiency of large intestine fermentation. I Agric Food Chem 58, 8952-8957.

30. Fastinger ND, Karr-Lilienthal LK, Spears JK, et al. (2008) A novel resistant maltodextrin alters gastrointestinal tolerance factors, fecal characteristics, and fecal microbiota in healthy adult humans. J Am Coll Nutr 27, 356-366.

31. Probert HM, Apajalahti JHA, Rautonen N, et al. (2004) Polydextrose, lactitol, and fructo-oligosaccharide fermentation by colonic bacteria in a three-stage continuous culture system. Appl Environ Microbiol 70, 4505-4511. 